\title{
D-Cycle as a core element of a digital transformation framework
}

\author{
Evgeny Popov ${ }^{1}$, Victoria. Simonova ${ }^{1}$, and Vitalii. Cherepanov ${ }^{1,2,{ }^{*}}$ \\ ${ }^{1}$ Center for social-economic researches of Ural Institute of Management, branch of RANERA, 66, \\ 8 Marta St., Ekaterinburg, 620144, Russia \\ ${ }^{2}$ Technological Processes and Production Automation and Mechanics Dept., Technical University of \\ UMMC, 3 Uspenskiy Ave., Verkhnyaya Pyshma, Russia
}

\begin{abstract}
A digital transformation process as an emerging management practice requires a clear, well-described and detailed toolset, that will be handful and easy to apply in practical everyday tasks in a digital transformation change process. In this research, the essential tool of a digital transformation process created by authors is described. Created by research's authors as D-Cycle, this tool allows to run a digital transformation of organisation, process, or it's segment from any transforming object's digital maturity level. D-Cycle will be useful as a key digital transformation tool in digital transformation programmes and day-to-day digital managers' activities. This tool is also suitable for creating more complicated digital transformation frameworks, those suit for tasks of large enterprises or massive social institutes. D-Cycle does not focus on any certain industry or social field, hence it's rather universal for solving digital transformation problems. Its practical concise content allows it to be used almost without any special competencies in digital transformation and makes it ready to be applied widely.
\end{abstract}

\section{Introduction}

A digital transformation has become a usual management practice. Today's managers' regular and strategic tasks are based on modern tools, redesigned processes, and so-called disruptive business models. All these tools and efforts are focused on digital changes those are to get more organizational efficiency, agility, and competitive advantages.

This tendency runs through organizational structures and business communities widely, so digital transformation tasks heavily draw the attention of managers all over the world.

Digital transformation even changed the way of modern labour. It has actually kicked off a gig economy phenomenon. This way of economic interactions is based on platforms and focused on certain actions instead of traditional work processes [11]. Finally, platform owner becomes a stakeholder of a labour field, which forms a playground for independent professionals.

Bain\&Co.'s insight on management tools and trends in a digital transformation field says that managers mainly focused on mature tech trends and on business tasks ${ }^{\dagger}$. Such

\footnotetext{
* Corresponding author: v.cherepanov@outlook.com
} 
issues demand clear common tools to run digital transformation tasks and programmes. But today we have in management practice only well-designed project management tools, mature practices of creating new ideas, and a bunch of ideas on how to run a digital transformation programme, but not a point on what to do in that process.

One of the most discussed ideas of digital transformation is that it helps make a new business, conquer new markets, or create brand new products or shift the accent on a service model for customers. All these digital transformation approaches have a solid basement, but it seems to be more realistic to reckon that digital transformation supports more customer-centric processes and connected market collaborations [5]. In addition to these business aims and changes those are based on digital transformation, there's a rising idea that the digital transformation core meaning is not to change an IT strategy, but to change an entire business with technological solutions transformation practice should be based on clear tools and practices, those will not be in a field of deep tech connoisseurs, but in the field of practical regular management.

The Open Group as an important participant of the IT market and a various methodologies provider developed and supports DPBoK - Digital Practitioner Body of Knowledge ${ }^{\S}$. This precious knowledge source describes in detail how to organize a digital transformation project in a company but doesn't deliver any idea on what could be done to transform a business or any process in it.

A kind of very practical approach is shown in research, that shows a link between good results in lean management and in a digital transformation management in an organization [10]. The researchers also concluded that there two types of digital transformation patterns: sustaining digital transformation pattern and disruptive digital transformation pattern. But the main differences between those patterns from the point of practical actions are not covered by the concept.

Not only tools and approaches, but policy and restrictions should be defined in digital transformation disruption changes [1]. This also means that inner governing processes in an organization should be well-designed and driven.

Digital transformation allows considering a business as a single entire agent on the market. It could be reached via an app or a website that crushes its image as a group of people. This leads to a demand for special competencies of firms' interactions on different markets. [2]. That shows digital transformational different perspectives of analysis: from an entire market to a local process.

These examples show that a need for practical digital transformation tools as a part of management practice is vital and such tools should be easy to explain and use.

\section{Digital transformation approaches}

Most researchers focused on a project management component of digital transformation. One of the main ideas is that project management tools and practices demand rises again within a digital transformation context [6].

But digital transformation project has its specific treat: significant disruptive changes are made by small deep experienced teams [7], those deliver a focused value of such changes.

\footnotetext{
$\dagger$ https://www.bain.com/insights/management-tools-digital-transformation/ - Digital Transformation, 2018

$\$$ https://enterprisersproject.com/article/2020/10/digital-transformation-3-hard-truths - Digital transformation: 3 hard truths

$\S$ https://www.opengroup.org/certifications/dpbok - Digital Practitioner Certification: DPBoK ${ }^{\mathrm{TM}}$

Foundation
} 
There is a very good example of transformation component concept, described by researchers from RANEPA in their practical complex of digital transformation practices on digital transformation strategy**. They use a term of a transforming solution. It's very precise in describing a point of using digital technologies to transform a process or an organization.

Some researchers suggest using a design thinking $\dagger \dagger$ approach [4] to find a point of applying digital technologies to make a process better. We share and appreciate this approach because there's no such efficient practice of finding new solutions, then design thinking approach.

But also, there is an original approach of decomposing a business into business services with digital interfaces, so-called Segregated Business Services Design [3]. This approach allows to make an alternative business structure based on services, those could be much easier transformed into digitally based procedures and interactions.

Some practitioners suggest using Business Model Canvas process $^{\S \S}$. This suggestion makes a transformational process a little bit clearer, but it doesn't support core changes.

Authors of this research have already published their main concept on digital transformation core terms [9] and defined key treats of digital technologies. The ones to the following:

- overcome time and space.

- enrich human's abilities.

- interconnect people, systems, and machines.

Deep dive into this approach has already yielded a concept of digital transformation core: it is a process of substitution of humans or analogous machines with digital technologies to make a process or an organization more efficient. One of the main our findings is that the final stage of a digital transformation that is equal to the final stage of digital maturity is an autonomous tech system, that could act and interact without human participation and even support. The main target of this developing transformation process is to embed such autonomous element into a more complicated system to get a business scale effect.

Further research in this field allowed to create a solid integrated digital transformation tool that was called D-Cycle.

\section{D-Cycle as a digital transformation tool}

Every manager and entrepreneur asks a question, whether a business is efficient enough. This question starts a chain of steps those leads to business changes. In a modern practice, these changes are almost based on digital technologies.

Decomposing this process, we found that there is a sustainable chain of actions, those could be integrated in a solid cycle leading a process or an organization to the next digital maturity level. This cycle was called D-Cycle and it has the following structure (Figure 1).

\footnotetext{
** https://strategy.cdto.ranepa.ru/ - Digital transformation strategy: write to execute (Стратегия цифровой трансформации: написать, чтобы выполнить)

${ }^{\dagger \dagger}$ https://hbr.org/2018/09/why-design-thinking-works - Leidtka J. "Why Design Thinking Works: It addresses the biases and behaviors that hamper innovation"

$\$$ https://www.strategyzer.com/blog/posts/2015/3/23/14-ways-to-apply-the-business-model-canvas -

14 Ways to Apply the Business Model Canvas

$\S \S$ https://www.thedigitaltransformationpeople.com/channels/strategy-and-innovation/beyond-thebusiness-model-canvas-2/ - Beyond the Business Model Canvas
} 


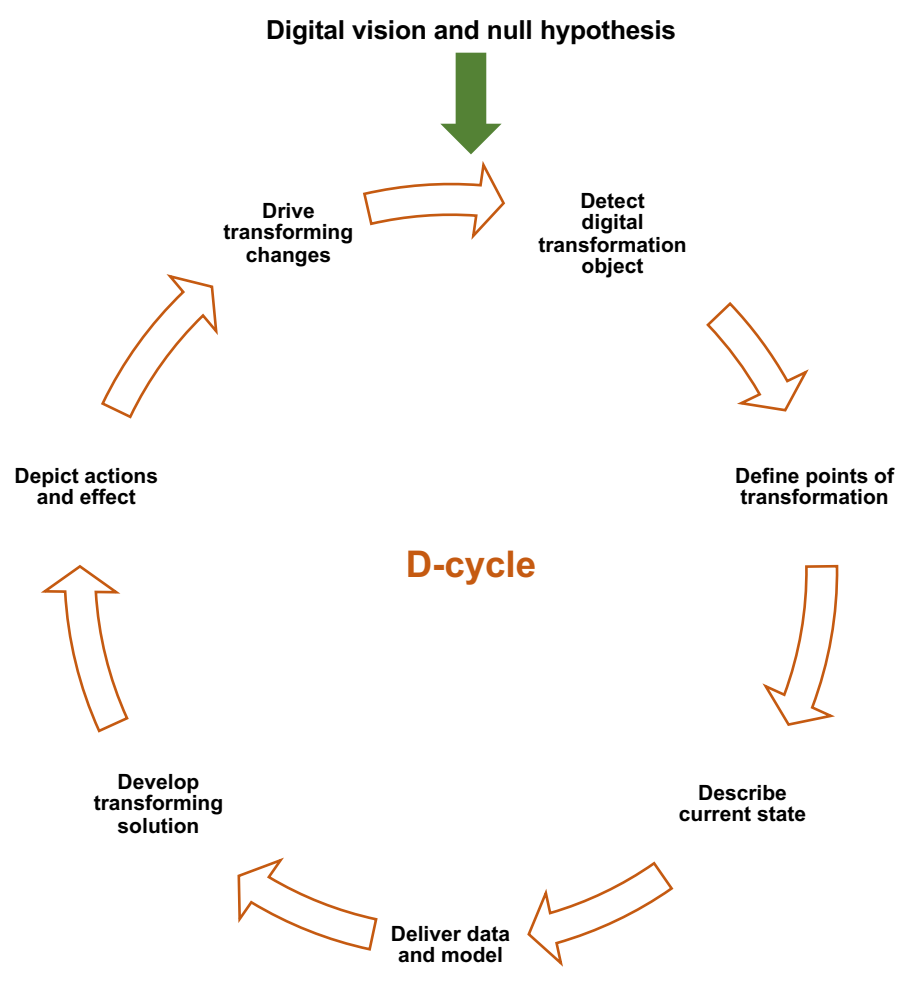

Fig. 1. Digital transformation cycle structure.

Every change takes its origin not only from the question whether system is quite efficient, but also from an initial hypothesis on what could be changed or which technological solutions lead to positive changes. This stage was called "Digital vision and null hypothesis" and led to the following cycle of activities, those could be applied to any process or an organization, so-called transforming object, to drive it to the next digital maturity level:

1. Detect digital transformation object - define all boundaries of a transforming object that should be changed under a digital transformation process.

2. Define points of transformation - find a point, where digital technologies yield highest possible results.

3. Describe current state - estimate current digital maturity level to find the best solution in the next stages.

4. Deliver data and model - create a digital twin and collect necessary data to estimate future results.

5. Develop transforming solutions - create the best solutions, those are based on digital twin estimates and desired digital maturity level.

6. Depict actions and effect - make necessary details of actions and possible effects.

7. Drive transforming changes - steer the digital transformation project.

Although these stages are rather clear, there is no possibility to run those ones without suitable tools. So, we made a more detailed picture of digital transformation and developed D-Cycle tool: 


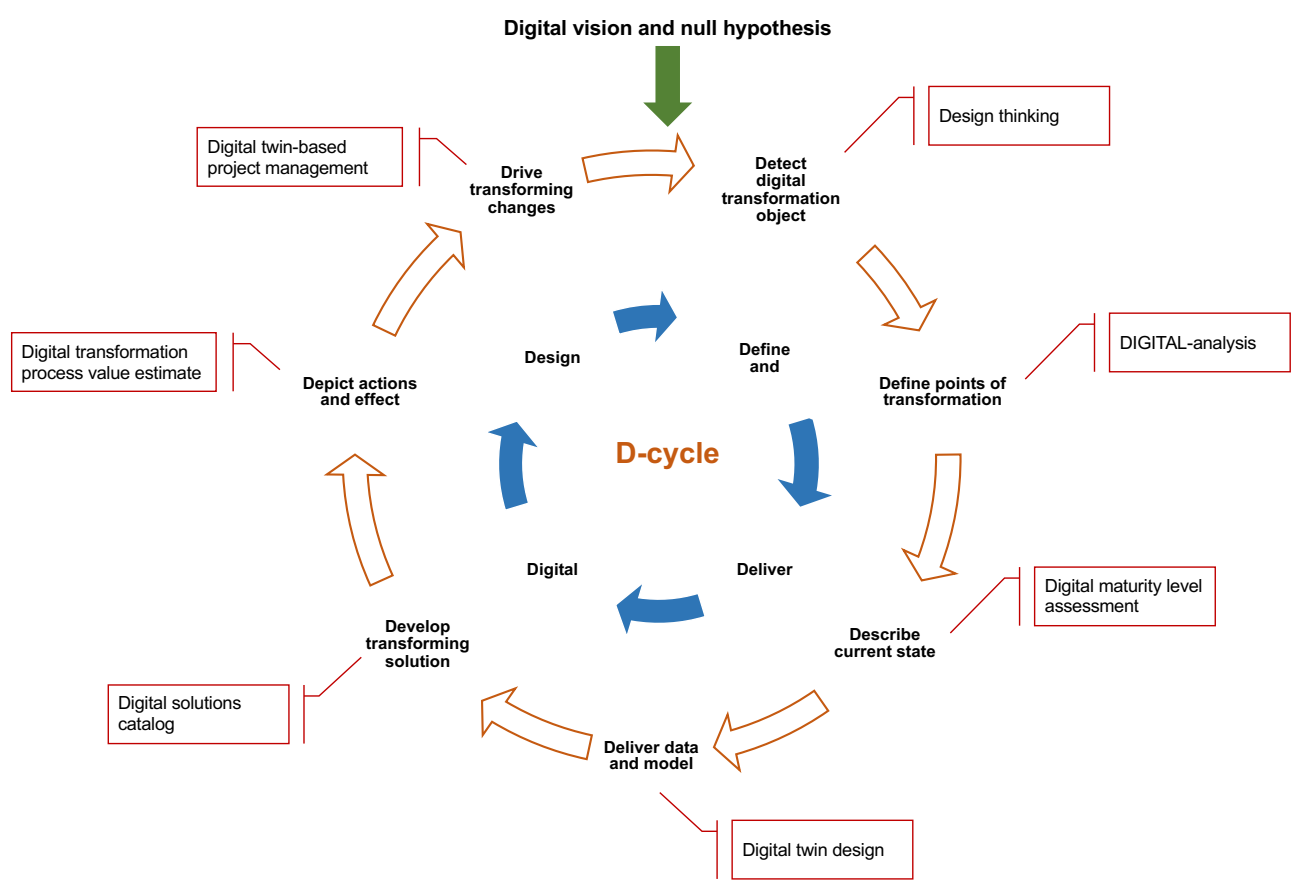

Fig. 2. D-Cycle structure and key components.

The stages of D-Cycle should be enriched with certain tools, those support every digital transformation stage:

Table 1. D-Cycle structure and tools.

\begin{tabular}{|c|c|c|c|}
\hline № & D-Cycle stage & Tool(s) & Comments \\
\hline 1. & $\begin{array}{l}\text { Detect digital } \\
\text { transformation object }\end{array}$ & Design thinking & $\begin{array}{l}\text { The best way to see digital transformation } \\
\text { boundaries is to use the design thinking } \\
\text { technique. It allows considering changed } \\
\text { states and take a detailed picture in what } \\
\text { should be changed. }\end{array}$ \\
\hline 2. & $\begin{array}{l}\text { Define points of } \\
\text { transformation }\end{array}$ & $\begin{array}{l}\text { DIGITAL- } \\
\text { Analysis }\end{array}$ & $\begin{array}{l}\text { DIGITAL-Analysis as a tool for defining a } \\
\text { point of digital transformation was } \\
\text { published by authors in special research [8] }\end{array}$ \\
\hline 3. & Describe current state & $\begin{array}{l}\text { Digital maturity } \\
\text { assessment }\end{array}$ & $\begin{array}{l}\text { Authors have already published a concept of } \\
\text { digital maturity levels, which describes the } \\
\text { extent of substitution of humans and } \\
\text { analogous machines with digital } \\
\text { technologies. }\end{array}$ \\
\hline 4. & $\begin{array}{l}\text { Deliver data and } \\
\text { model }\end{array}$ & $\begin{array}{l}\text { Digital twin and } \\
\text { data analysis } \\
\text { techniques }\end{array}$ & $\begin{array}{l}\text { Digital twin allows estimating what results } \\
\text { could be reached if a transforming object } \\
\text { will be run in other conditions and with } \\
\text { other technologies. }\end{array}$ \\
\hline 5. & $\begin{array}{l}\text { Develop transforming } \\
\text { solutions }\end{array}$ & $\begin{array}{l}\text { Digital solutions } \\
\text { catalog } \\
\text { Design thinking }\end{array}$ & $\begin{array}{l}\text { Digital technologies should be standardized } \\
\text { in an organization. The better way is to } \\
\text { shape organization's own digital solutions } \\
\text { catalog. If there is not any, the best way is to } \\
\text { use the design thinking technique again. }\end{array}$ \\
\hline
\end{tabular}


Continuation of table 1.

\begin{tabular}{|l|l|l|l|} 
6. & $\begin{array}{l}\text { Depict actions and } \\
\text { effect }\end{array}$ & $\begin{array}{l}\text { Digital } \\
\text { transformation } \\
\text { process estimate }\end{array}$ & $\begin{array}{l}\text { The key idea of the estimate is to compare } \\
\text { the cost of a transforming object before } \\
\text { and after transformation. If there is a } \\
\text { positive difference, the transformation } \\
\text { could be run. This idea will be developed } \\
\text { in the stan-alone research. }\end{array}$ \\
\hline 7. & $\begin{array}{l}\text { Drive transforming } \\
\text { changes }\end{array}$ & $\begin{array}{l}\text { Digital twin-based } \\
\text { project } \\
\text { management }\end{array}$ & $\begin{array}{l}\text { Digital transformation couldn't be based } \\
\text { only on traditional approaches of project } \\
\text { management. If the result should be } \\
\text { maximum, the project should be run based } \\
\text { on digital twin estimates and goals. }\end{array}$ \\
\hline
\end{tabular}

The designed tool covers all the stages of a digital transformation process. D-Cycle should be adopted in any organization, where it is going to be used. But the core structure, tools, and the idea of growing digital maturity level in every digital transformation cycle is a core of the concept and could be applied in every context.

\section{D-Cycle practical value}

The work done in this research had not only scientific but also practical goals. Those ones were reached by a valuation of D-Cycle's practical value. This analysis allowed us to conclude that D-Cycle has the following practical applications:

1. It allows making a structure of a digital transformation project.

2. It allows running a digital transformation project according to a clear path, which could be a basement of a digital transformation roadmap.

3. D-Cycle allows making a step from abstract changes towards practical transformation actions.

The main practical value of the D-Cycle is that it could be used almost without deep preparation to any organization or process.

D-Cycle as a tool could be used as a structure of a deep detailed digital transformation framework. A clear and connected structure of the D-Cycle allows using it in different situations and practices almost without prior intensive preparations.

\section{Conclusions}

A described key tool of a digital transformation that we called D-Cycle could be used in large-scale digital transformation projects and programmes. It could also be put into a basement of various digital transformation frameworks.

Further author's efforts will be focused on digital transformation effect estimation and distinctive features of a digital transformation execution procedure. These results will be published with a linkage to D-Cycle, which becomes a core digital transformation tool developed by authors.

\section{References}

1. P. Depaoli, M. Sorrentino, M. De Marco, Digital Transformation and Human Behaviour (2020)

2. C. C. Gernreich, C. Ahlfeld, S. Knop, Digitalization (2021) 
3. J. Gotze, A. Romanov, Architecting the Digital Transformation (2021)

4. K. Gurusamy, N. Srinivasaraghavan, S. Adikari, International conference of design, user experience and usability (2016)

5. A. Hamlet, R. Bohnsack, D. Marz, C.A. Marante, Journal of Management studies (2020)

6. F.S. Karla, A. Soyer, Handbook of Research on Management and Strategies for Digital Enterprise Transformation (2021)

7. N. Perkin, P. Abraham, Building the agile business through digital transformation, Second edition (2021)

8. E. V. Popov, V.L. Simonova, V.V. Cherepanov, Ekonomika i upravlenie $=$ Economics and Management, 27 (9), 672-686 (2021)

9. E. V. Popov, V. L. Simonova, V. V. Cherepanov, Journal of New Economy, 22 (2) (2021)

10. M. Rossini, F. D. Cifone, B. Kassem, F. Costa, A. Portioli-Staudacher, Journal of Manufacturing Technology Management, 32 (9) (2021)

11. J. Woodcock, M. Graham, The Gig Economy: a critical introduction», (Wiley, 2020) 